\title{
Bone Mineral Deficiency as the Main Factor of Dolichocephalic Head Flattening in Very-Low- Birth-Weight Infants ${ }^{1}$
}

\author{
FRANK POHLANDT \\ Division of Neonatology' and Pediatric Critical Care Medicine, Children's Hospital, University of Ulm. \\ Ulm, Germany
}

\begin{abstract}
We hypothesized that the postnatally reduced rate of bone mineralization observed in many verylow-birth-weight (VLBW) infants is the main cause of dolichocephalic flattening of the head in this group of newborns. We measured head shape by using the ratio of the frontooccipital and biparietal diameters, bone mineral content (BMC) at the right midhumerus, birth weight, body weight, and postnatal age at the time of BMC measurement in 85 newborn infants during the first $5 \mathrm{~d}$ of life (gestational age: median 34 wk, range $24-40$ wk; birth weight: median $1.590 \mathrm{~g}$, range $430-6.730 \mathrm{~g}$ ) and in 269 VLBW infants at transfer to other hospitals or discharge. The head shape shortly after birth was not influenced by gestational age. Mean frontooccipital diameter/biparietal diameter was 1.27 $\pm 0.73 \mathrm{SD}$ (range 1.13-1.59). Stepwise multiple regression analysis from 315 measurements made in $46 \mathrm{VLBW}$ infants during the first $5 \mathrm{~d}$ after birth and the 269 infants at discharge revealed a $27 \%$ contribution of BMC/body weight to the variation in head shape. The other variables had only a small effect (gestational age $4 \%$, body weight $1 \%$ ) or no observable effect on head shape. At discharge, the ratio of BMC to body weight was significantly lower than in the reference fetuses of the same body weight. The results support the hypothesis, and we speculate that there is a causal relationship between the head shape of VLBW infants at discharge and the amount of calcium and phosphorus given as a supplement until that time. (Pediatr Res 35: 701-703, 1994)
\end{abstract}

\section{Abbreviations}

BPD, biparietal diameter BMC, bone mineral content FOD, frontooccipital diameter VLBW, very low birth weight

In VLBW infants, the shape of the skull is often deformed with increasing postnatal age into a dolichocephalic shape combined with flattening in the frontal axis. This deformation is so commonly observed that it seems to be an inborn and physiologic feature of the VLBW infant. Baum and Searls (1) addressed this phenomenon and undertook the first longitudinal study to investigate the deformation of head shape in preterm low-birth-

Received November 26, 1992; accepted December 23, 1993.

Correspondence and reprint requests: Frank Pohlandt. M.D., Ph.D.. Universitäts-Kinderklinik, D-89070 Ulm, Germany.

Supported by Grant Po 187/2-1 from the Deutsche Forschungsgemeinschaft.

'Presented in part at the annual meeting of the ESPR. June 1992. Uppsala. Sweden. weight infants. The cause or causes of this deformation, which persists into adulthood, were not explained.

A simple mechanistic model indicates that the power of gravity is usually the main factor in flattening of the skull of preterm infants when they lie on their side. As for the main factor that counteracts this power, only the mineral content of the skull is known to give the skull its firmness. However, the BMC does not increase with postnatal age, as it would in utero, in those VLBW infants who do not receive enough calcium and phosphorus to meet the requirements of their rapidly growing skeleton (2). As a result, the balance between the deforming power of gravity and the counteracting firmness of the skull is shifted in favor of gravity. It is our hypothesis that the reduced rate of bone mineralization that occurs in many VLBW infants is the main cause of the dolichocephalic head flattening in this group of newborns.

In this study, BMC of the right midhumerus and head shape were measured in a reference group shortly after birth and in VLBW infants at discharge to test our hypothesis.

\section{MATERIALS AND METHODS}

BMC of the right midhumerus. FOD, BPD, and body weight were measured at the same time 1 ) during the first $5 \mathrm{~d}$ after birth in 85 newborn infants and 2) in 269 preterm infants on the day of transfer to other hospitals or at discharge (Table 1).

BMC was measured by single-photon absorption densitometry as described previously (3). The precision of this measurement was $3 \%$. Gestational age was calculated from ultrasound measurements during early gestation and menstrual history. Body weight was measured by an electronic scale to the nearest $10 \mathrm{~g}$. FOD and BPD were measured with calipers. After the instrument was moved in both positions, the highest reading was recorded. The coefficient of variation was $0.7 \%$.

The contributions of BMC/body weight, gestational age, postnatal age, and body weight to the variation in head shape (ratio of FOD to BPD) were calculated in a stepwise multiple regression analysis of 315 measurements made in 46 VLBW infants during the first $5 \mathrm{~d}$ after birth and in $269 \mathrm{VLBW}$ infants at the time of transfer to other hospitals or at discharge (Table 1).

\section{RESULTS}

Shortly after birth, we found a nearly constant head shape, expressed as the ratio of FOD to BPD, in infants from 24 to 42 wk gestational age and 430 to $6.760 \mathrm{~g}$ birth weight (Fig. 1). The mean FOD/BPD was $1.27 \pm 0.073 \mathrm{SD}$ (range 1.13-1.59).

The stepwise multiple regression analysis (Table 2 ) revealed the ratio of BMC to body weight at the time of BMC measurement to be the main factor contributing to the variation in head shape with increasing postnatal age (26.5\%). Gestational age and body weight at the time of BMC measurement contributed $4 \%$ 
Table 1. Characteristics of the infants

\begin{tabular}{|c|c|c|}
\hline & $\begin{array}{l}\text { Newborn } \\
\text { infants during } \\
\text { the first } 5 \mathrm{~d} \\
\text { after birth }\end{array}$ & $\begin{array}{l}\text { VLBW infants } \\
\text { studied by } \\
\text { multiple stepwise } \\
\text { regression } \\
\text { analysis } \\
\end{array}$ \\
\hline Number & 85 & 314 \\
\hline \multicolumn{3}{|c|}{ Gestational age (wk) } \\
\hline Median & 34 & 28 \\
\hline Range & $25-42$ & $24-36$ \\
\hline \multicolumn{3}{|c|}{ Birth weight (g) } \\
\hline Median & 1590 & 1000 \\
\hline Range & $750-6760$ & $430-1500$ \\
\hline \multicolumn{3}{|c|}{ Body weight (g) } \\
\hline Median & & 1660 \\
\hline Range & & $660-4150$ \\
\hline \multicolumn{3}{|c|}{ Postnatal age (wk) } \\
\hline Median & & 6.1 \\
\hline Range & & $0.1-26.3$ \\
\hline \multicolumn{3}{|c|}{ Postmenstrual age (wk) } \\
\hline Median & & 35.0 \\
\hline Range & & $26.0-57.9$ \\
\hline
\end{tabular}

and $1 \%$, respectively. Birth weight and postnatal age did not reach the significance level for entry into the model.

The ratio of BMC to body weight was considerably lower in VLBW infants at discharge (age $>6 \mathrm{wk}$ ) than in the reference fetus of the same body weight (3) (Fig. 2). The median ratio of FOD to BPD at transfer or discharge was 1.49 (range 1.04-1.70).

\section{DISCUSSION}

Using the ratio of FOD to BPD as an index of head shape, we found a nearly constant value (1.27) in newborn infants of 24 to $40 \mathrm{wk}$ gestational age during the first $5 \mathrm{~d}$ after birth, i.e. the head shape after birth is not influenced by gestational age. Baum and Searls (1) achieved similar results (a ratio of approximately 1.3 ) with a different, indirect measuring technique.

In that study, all 14 preterm low-birth-weight infants followed longitudinally with serial measurements of head shape showed the same pattern of progressive dolichocephalic flattening. In our study, in contrast, most of the 269 VLBW infants showed no or only slight flattening at discharge (Table 1), although their birth weights were considerably lower, i.e. the infants of this study were more prone to dolichocephalic flattening. We did not try to prevent the flattening of the skull by specially positioning the head or by any other physical measure. Therefore, the rigidity of the skull as the main power against gravity must have been stronger than it was in the infants studied by Baum and Searls. The reason for this is probably our protocol of supplementation with calcium and phosphorus. All VLBW infants received supplements of calcium gluconate, calcium glycerophosphate, or both that were increased stepwise until a simultaneous excretion of calcium and inorganic phosphorus with urine $(1-2 \mathrm{mmol} / \mathrm{L})$ was achieved. This technique of adjusting the supplements to the individual needs and to the mineral absorption rates leads to achievement of the intrauterine mineral accretion rate in VLBW infants $(4,5)$ and prevents the postnatal decrease in the mineralization rate always seen in unsupplemented VLBW infants. Thus, the skull is kept firm and resistant to the deforming power of gravity.

Although there are no data available on the incidence of dolichocephalic deformation, it is my experience that it is most often found in extremely low-birth-weight infants. Therefore, gestational age and birth weight were expected to contribute significantly to the head shape at discharge, as was postnatal age, inasmuch as gravity needs some time to bring about flattening of the head. Surprisingly, the stepwise multiple regression analysis revealed BMC to be the factor that predominantly contributed

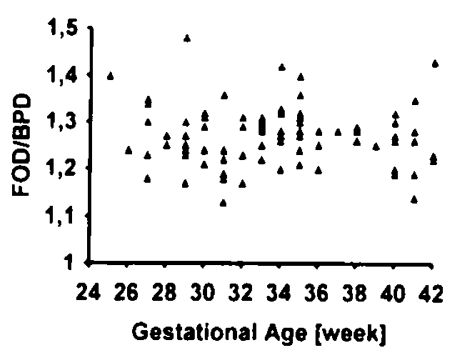

Fig. 1. Head shape using the ratio of FOD to BPD in 85 newborn infants.

Table 2. Multiple stepwise regression analysis of factors possibly contributing to head shape in low-birth-weight infants

\begin{tabular}{clcccc}
\hline $\begin{array}{c}\text { Step } \\
\text { no. }\end{array}$ & \multicolumn{1}{c}{ Variable } & Multiple & Multiple & & \\
\hline 1 & BMC/body weight & 0.515 & 0.265 & 84 & $<0.01$ \\
2 & Gestational age & 0.552 & 0.304 & 13 & $<0.01$ \\
3 & Body weight & 0.563 & 0.317 & 4.4 & $<0.05$ \\
4 & Birth weight* & & & & \\
5 & Postnatal age* & & & & \\
\hline
\end{tabular}

* Did not reach the significance level for entry into the model.

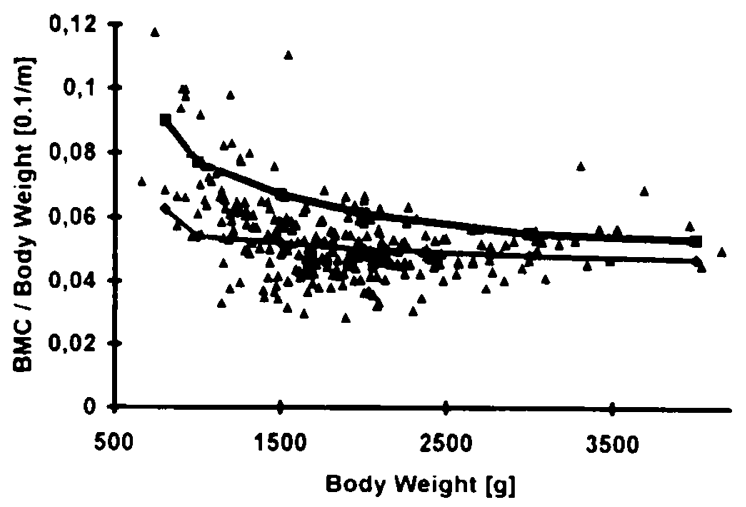

Fig. 2. BMC in relation to body weight in $269 \mathrm{VLBW}$ infants at the time of transfer to other hospitals or discharge. $\mathrm{BMC}$, body weight in the reference fetus, 50th percentile: $\Delta, 2.5$ th percentile, calculated from previously reported data (3)

to the variation in the degree of dolichocephalic flattening with postnatal age. All other studied variables had a negligible influence or no influence on head shape, because there is a relationship between BMC/body weight and the four variables gestational age, birth weight, postnatal age, and body weight at measurement. These four variables only seem to have an effect on the head shape: Given a calcium-phosphorus supplementation that does not meet the infant's need, the mineralization rate will be lower than in utero and the deficit in BMC will increase with postnatal age. At discharge, infants with the youngest gestational ages and the lowest birth weights will have the highest postnatal ages and the lowest BMC/body weight ratios. These correlations explain why gestational age, birth weight, and postnatal age did not contribute significantly to the variation in head shape after the $\mathrm{BMC} /$ body weight ratio had reached the highest level of significance for entry into the model. The BMC to body weight ratio is the only of the variables that can be causally related to the head shape. These findings support our hypothesis that a postnatally decreasing mineralization rate and the consequent low BMC/weight ratio are a main cause of dolichocephalic head flattening in VLBW infants.

Our observation was made during a study concerning the prevention of bone mineral deficiency in preterm infants by supplementation with calcium and phosphorus. Possible side effects such as necrotizing enterocolitis and nephrocalcinosis 
were not observed (5). Although the prevention of fractures in preterm infants is a generally accepted goal, the preservation of the head shape observed at birth by supplementation with calcium and phosphorus has not been discussed until now. The possible long-term effects of the flattening in the frontal axis on orthodontic and rhinologic problems seem obvious but have not been studied. We have some evidence that myopia often found in former VLBW infants is caused by protrusion and ellipsoid deformation of the spherical eyeballs as a result of the flattening in the frontal axis and can be prevented by supplementation with calcium and phosphorus (6). Additional studies are needed to investigate the long-term effects of dolichocephalic deformation in VLBW infants.

For technical reasons, BMC was measured at the right midhumerus but not at the skull, which might weaken our arguments. Although there are no studies comparing the BMC of different parts of the skeleton in newborns, we see no reason not to assume that the changes in the BMC of the midhumerus are representative of changes in other parts of the skeleton of VLBW infants. A confirmation of our findings by measuring the BMC of the skull would be desirable.

\section{REFERENCES}

1. Baum JD, Searls D 1971 Head shape and size of preterm low-birth-weight infants. Dev Med Child Neurol 13:576-581

2. Shaw JCL 1973 Parenteral nutrition in the management of sick low-birthweight infants. Pediatr Clin North Am 20:333-358

3. Pohlandt F, Mathers N 1989 Bone mineral content of appropriate and light for gestational age preterm and term newborn infants. Acta Paediatr Scand 78:835-839

4. Pohlandt F 1988 Vermeidung der Skelettdemineralisierung bei sehr kleinen Frühgeborenen. Individuelle Steuerung der Kalzium- und Phosphatsubstitution anhand der Kalzium-. Phosphatkonzentration im Urin. In: Nars PW (ed) Pädiatrische Intensivmedizin IX. Georg Thieme Verlag, Stuttgart, Ger-

many, pp $100-102$
5. Pohlandt F 1994 Prevention of postnatal bone demineralization in very lowbirth-weight infants by individually monitored supplementation with calcium and phosphorus. Pediatr Res 35:125-129

6. Pohlandt F 1994 Hypothesis: myopia of prematurity is caused by postnatal bone mineral deficiency. Eur J Pediatr 153:234-236 